\title{
Effects of Polychlorinated Biphenyls on the Development of Neuronal Cells in Growth Period; Structure-Activity Relationship
}

\author{
Youngrok Do and Dong Kuck Lee* \\ Department of Neurology, Catholic University of Daegu School of Medicine, Daegu 705-718, Korea
}

\begin{abstract}
Polychlorinated biphenyls (PCBs) are accumulated in our body through food chain and cause a variety of adverse health effects including neurotoxicities such as cognitive deficits and motor dysfunction. In particular, neonates are considered as a high risk group for the neurotoxicity of PCBs exposure. The present study attempted to analyze the structure-activity relationship among PCB congeners and the mechanism of PCBs-induced neurotoxicity. We measured total protein kinase C (PKC) activities, PKC isoforms, reactive oxygen species (ROS), and induction of neurogranin (RC-3) and growth associated protein-43 (GAP-43) mRNA in cerebellar granule cells of neonatal rats with phorbol 12, 13-dibutyrate ( $\left.\left[{ }^{3} \mathrm{H}\right] \mathrm{PDBu}\right)$ binding assay, western blot, ROS assay, and reverse transcription PCR (RT-PCR) analysis respectively following the different structural PCBs exposure. Only non-coplanar PCBs showed a significant increase of total PKC- $\alpha$ and $\beta I I$ activity as measured with $\left[{ }^{3} \mathrm{H}\right] \mathrm{PDBu}$ binding assay. ROS were more increased with non-coplanar PCBs than coplanar PCBs. The mRNA levels of RC-3 and GAP-43 were more induced with noncoplanar PCBs than coplanar PCBs, indicating that these factors may be useful biomarkers for differentiating non-coplanar PCBs from coplanar PCBs. Non-coplanar PCBs may be more potent neurotoxic congeners than coplanar PCBs. This study provides evidences that non-coplanar PCBs, which have been neglected in the risk assessment processes, should be added in the future to improve the quality and accuracy of risk assessment on the neuroendocrinal adverse effects of PCBs exposures.
\end{abstract}

Key words: neurotoxicity syndrome, polychlorinated biphenyls, structure-activity relationship, protein kinase C, reactive oxygen species, Nerve growth factor

\section{INTRODUCTION}

Polychlorinated biphenyls (PCBs) are typical aromatic environmental pollutants that are accumulated through the food chain, prevail around us, and can possibly harm the human body. PCBs, which have been used widely as industrial materials for the past

Received December 24, 2011, Accepted February 2, 2012

${ }^{*}$ To whom correspondence should be addressed. TEL: 82-53-650-4267, FAX: 82-53-654-9786

e-mail: dklee@cu.ac.kr decades, also cause environmental pollution on a continuous basis through industrial products have been generated in the past [1]. PCBs are characterized by carcinogenicity, reproductive toxicity, and immunotoxicity and have recently been known to disrupt neurotransmitters [2-4]. In animal testing, PCBs, which disrupt control of neurotransmitters and thyroid hormone in the brain, hinder normal brain development and exert effects on intellectual developments, such as behavior, cognition, and memory. These effects are known to be more serious especially in the brain of fetuses or infants where neuronal cells are developing actively [5].

PCBs have 209 theoretical congeners, the chemical structures
Copyright $\odot$ Experimental Neurobiology 2012. www.enjournal.org
This is an Open Access article distributed under the terms of the Creative Commons Attribution Non-Commercial License (http://creativecommons.org/licenses/by-nc/3.0) which permits unrestricted non-commercial use, distribution, and reproduction in any medium, provided the original work is properly cited. 
of which can make differences to toxicities; therefore, toxic actions based on the structures are important in assessing their toxicities. Since dioxin and dioxin-like compounds are known to make diverse toxic actions via the medium of an aryl hydrocarbon (Ah) receptor, the Toxic Equivalent Factor (TEF), which assesses toxicity on the basis of reaction to an Ah receptor, has been introduced to the concept of toxicity assessment [1]. PCBs are divided into coplanar (dioxin-like) PCBs reacting to an Ah receptor and non-coplanar (non-dioxin-like) PCBs with no affinity to an Ah receptor. The former has a similar structure to dioxin and makes similar toxic actions to dioxin while the latter tends to be neglected in risk assessment since it has shown no remarkable action mechanism or serious toxicity. However, the results of animal testing show that when Aroclor 1256 with both coplanar and non-coplanar structures is administered noncoplanar structure is mostly accumulated in the brain [6]. Since non-coplanar PCBs have greater effects on the changes in neural development in brain cells than coplanar PCBs, many researches are being conducted on neurotoxicities of non-coplanar PCBs [7]. As non-coplanar PCBs have recently been known to have no reaction to an Ah receptor but be sensitive to the secondary signaling system and neurotransmitters of the brain, be detected most frequently in breast milk, and be able to affect intellectual and behavioral development of young children, it is necessary to introduce a new concept of risk assessment [8].

Non-coplanar PCBs are known to activate protein kinase $\mathrm{C}$ (PKC) in cerebellar granule cells. PKC has 11 congeners or more, which vary in their intracellular distribution or action. While PKC- $\alpha$ and PKC- $\varepsilon$ were shown to be target substances for 2,2'-dichlorobiphenyl [4], it is not known what PKC congeners are targets for PCB congeners and how their intracellular distribution varies.

It is known that PCBs decrease thyroid hormone (T4) of the brain in the growth period and that the decrease in thyroid hormone of the brain is closely related to oxidative stress [9]. Dioxin-like compounds greatly increase cytochrome p450 (CYP1A1, 1A2) via an Ah receptor. This increase in metabolic enzyme forms reactive-oxygen metabolites and causes oxidant stress [10]. As an important signal to cause such phenomena as apoptosis, the oxidative stress is also known to affect the cell cycle and have association with hypothyroidism in the growth-phase brain. So while oxidative stress may be a main action mechanism of PCBs-induced neuroendocrine disruption, there has been no research on this issue.

Neurotoxicity related to neuroendocrine disruption is getting much attention as a new feature of PCBs $[8,11]$. PCBs neurotoxicities related to the neuroendocrine system cause changing of signaling pathway, hindrance to dopamine and serotonin synthesis, and decreased thyroid hormone in the growth-phase brain. Among them, the decrease in thyroid hormone is a typical phenomenon, which can transform neurofilament present within neuronal cells and prevent normal cell growth. In particular, thyroid hormone plays an important role in extracellular matrices, such as myelin-associated glycoprotein, Tenescin-C, GAP (growth associated protein)-43, and fibronectin, which are involved in neuronal cell migration and development [12-14]. Thyroid hormone is also known to control PKC activity through neurogranin (RC-3), which is a PKC matrix present in the brain alone [15]. However, relations between many types of PCBs and extracellular matrices are rarely researched.

This study aims to analyze a neural action mechanism for different structural PCBs affecting growth and development of neuronal cells and control of neuroendocrine hormone in order to help the understanding of the effects of PCBs on neurotoxicity. An attempt is also made to help efficient risk assessment of PCBs and provide basic data to assess neurotoxicity more efficiently via developing a biomarker sensitive to the structural features.

\section{MATERIALS AND METHODS}

\section{Reagents and materials}

This study used Polychlorinated biphenyls (PCBs) produced by AccuStandard (New Haven, CT, USA) and other essential reagents produced by Sigma-Aldrich (St. Louis, MO, USA). Reagents related to cell culture, including Dulbeccos modified Eagle's medium (DMEM), were purchased from Gibco BRL (Gaithersburg, MD, USA), and those related to assessment of reactive oxygen species from Promega (Madison, WI, USA). The following PCB congeners were selected to make a relative comparison between coplanar and non-coplanar structures: 3,3',4,4,5-Penta-CB (PCB 126), 3,3',4,4,5,5'-Hexa-CB (PCB 169), 2,2'-Di-CB (PCB 4), and Aroclor 1256.

\section{Methods}

Cytotoxicity test: Cells were treated with PCBs for 24 hours and centrifuged to isolate cells from a cell culture medium. 1\% concentration of Triton X-100 was finally added to the isolated cells, which were then observed for 30 minutes for lysation. 100 $\mu \mathrm{l}$ of $4.6 \mathrm{mM}$ pyruvic acid and $100 \mu \mathrm{l}$ of $0.4 \mathrm{mg} / \mathrm{ml} \beta-\mathrm{NADPH}$ were mixed with the cell culture medium and cell lysate, respectively, with absorbance measured at $340 \mathrm{~nm}$. As for lactate dehydrogenase $(\mathrm{LDH})$ isolation, $\mathrm{LDH}$ activities measured in the cell culture medium and cell lysate, respectively, were revised in volumes to present as a percentage of $\mathrm{LDH}$ isolated from the total 
$\mathrm{LDH}$.

Cerebellar granule cell culture: Since neurotoxicity of PCBs is closely related to the cerebellum and the brain of newborn babies at the active growth phase is especially sensitive to it, this study used a 7-day-old cerebellar granule cell at the active growth phase as an experimental model. The cerebellum of a 7-day-old Sprague-Dawley (SD) rat was isolated and treated with trypsin. The final cell concentration was fixed at $1 \times 10^{6}$ cells $/ \mathrm{ml} ; 1.5 \mathrm{ml}$ cell suspension was added to the 12 -well culture plate treated with poly-L-lysine, which was then cultured in a $5 \% \mathrm{CO}_{2}$ incubator at $37^{\circ} \mathrm{C}$. Cytosine arabinoside $(5 \mu \mathrm{M})$ was administered to inhibit growth of non-neuronal cells 24 to 48 hours after cell implantation [7]. It was cultured for 7 days and, then, exposed to endocrine disruptors.

$\left[{ }^{3} \mathrm{H}\right]$ phorbol ester binding: Cells cultured in a 12-well culture plate for 7 days were cleansed with Locke's buffer $(154 \mathrm{mM}$ $\mathrm{NaCl}, 5.6 \mathrm{mM} \mathrm{KCl}, 3.6 \mathrm{mM} \mathrm{NaHCO}{ }^{3}, 2.3 \mathrm{mM} \mathrm{CaCl}{ }^{2}, 5.6 \mathrm{mM}$ D-glucose, $5 \mathrm{mM}$ Hepes, $\mathrm{pH}$ 7.4) and cultured for 15 minutes with Locke's buffer containing $1 \mathrm{nM}\left[{ }^{3} \mathrm{H}\right] \mathrm{PDBu}$ (phorbol 12,13-dibutyrate) and experimental materials. After removing the culture medium, it was cleansed with a buffer solution three times and made turbid by $1 \mathrm{ml}$ of $0.1 \mathrm{M} \mathrm{NaOH}$; then, $0.7 \mathrm{ml}$ of it was mixed with $9 \mathrm{ml}$ of Ultima gold to measure radioactivity with scintillation spectroscopy [7].

Cell fractionation: To extract PKC isozyme from between cytosol and membrane fraction, the cultured cell or brain tissue exposed to an environmental pollutant was treated with buffer $\mathrm{A}$ (20 mM Tris-HCl, pH 7.5, 0.25 M sucrose, 2 mM EDTA, protease inhibitors, $0.5 \mathrm{mM}$ phenylmethylsulfonylfluoride (PMSF), $10 \mu \mathrm{g} /$ $\mathrm{ml}$ leupeptin, $10 \mu \mathrm{g} / \mathrm{ml}$ pepstatin). By implementing centrifugation at $100,000 \times \mathrm{g}$ for an hour after sonication, the upper layer was isolated with cytosol fraction, deposits were extracted with buffer B (20 mM Tris-HCl, pH 7.5, 1\% Nonidet P-40, 150 mM NaCl, 1 mM EGTA, 1mM EDTA, protease inhibitors) for 30 minutes and centrifuged, and supernatant was isolated with detergent-soluble membrane fraction.

Western blot: Western blot was performed on cellular fraction to measure the changes in PKC congeners. A sample of cellular fraction was electrophoresed (7.5\% SDS-PAGE) in 12.5\% gel, blotted on nitrocellulose paper at $400 \mathrm{~mA}$ using Bio-rad's transfer chamber for 4 hours, and made to react with blocking buffer for an hour, with each of monoclonal or polyclonal antibodies diluted at a proper level and made to react for an hour. It was cleansed twice with Tris-buffered saline, made to react with secondary $\operatorname{IgG}$ for an hour, made to react using an enhanced chemiluminescence (ECL) system, exposed to an X-ray film for the optimum period of time, and developed [16].
Analysis of reactive oxygen species (ROS): 2'7'-dichlorofluorescein diacetate (DCFH-DA) is lipophilic, passes well into cells, and is transformed into the fluorescent material 2',7'-dichlorofluorescein (DCF) by hydrogen peroxide and peroxidase within cells. So it is widely used to measure activities of intracellular ROS through DCE measurements. After cell culture in a 12-well culture plate, it was cleansed with lock's buffer, treated with the fluorescent material DCFH-DA in a darkroom for 15 minutes, cleansed again, given cell lysis with $\mathrm{NaOH}$, and measured at excitation $488 \mathrm{~nm}$ and emission $525 \mathrm{~nm}$ using luminescence spectrometer. Other details of the procedure are based on other studies [17]. To evaluate interactions with mercury well known as a neurotoxic material, comparison was made between treatment with mercury chloride alone and co-treatment with PCBs.

\section{Reverse transcription-polymerase chain reaction (RT-}

$\boldsymbol{P C R}$ ): Since neuroendocrine hormone control disorder is closely related to changes in extracellular matrices of neuronal cells, mRNA manifestation of RC-3 and GAP-43, which are extracellular matrices related to neuronal cell migration and development, was analyzed using RT-PCR to assess the effects on growth and development of neuronal cells. Total RNA was extracted from the cells, oligo $\mathrm{d}(\mathrm{T})$ primer was added to $1 \mu \mathrm{g}$ of total RNA, which was then made to react at $60^{\circ} \mathrm{C}$ for 5 minutes to recover mRNA. $30 \mu \mathrm{RT}$ mix (0.1 M DTT, RNA guard, RTbuffer, dNTP, $\mathrm{dH}_{2} \mathrm{O}, \mathrm{RT}$ ) was added to each sample, which was then stagnated at $37^{\circ} \mathrm{C}$ for 60 minutes and at $70^{\circ} \mathrm{C}$ for 10 minutes and stored in ice to synthesize cDNA. After the cDNA process, $47.5 \mu$ of PCR mix [PCR-buffer, $\mathrm{dH}_{2} \mathrm{O}$, Taq polymerase, 5'-primer, 3'-primer, dNTP-mix ( ${ }^{32}$ P-labelled)] was added to $2.5 \mu \mathrm{l}$ of cDNA, and annealing temperature and the number of cycles were fixed at the optimum level on the basis of primer. Primer sets for Interleukin-1 (Forward: ATGGCGAGAAGTACCTAAGCT, Reverse: ACACAAATTGCATGGTGAAGT), Interleukin-6 (Forward: ATGAACTCCTTCTCCACAAGCGC, Reverse: GAAGAGCCCTCAGGCTGGACTG), Tumor necrosis factor- $\alpha$ (Forward: ATGAGCACAGAAAGCATGATC, Reverse: TACAGGCTTGTCACTCGAATT), and GAPDH (Forward: GCACAGTCAAGGCCGAGAAT, Reverse: GCCTTCTCCATGGTGGTGAA) were used (Table 1). It was electrophoresed in 10\% PAGE, dried with a gel dryer, stored in an $\mathrm{X}$-ray cassette at $75^{\circ} \mathrm{C}$ below zero, and developed [16].

\section{RESULTS}

\section{Neurotoxicity}

$0.1 \mu \mathrm{M}$ to $200 \mu \mathrm{M}$ PCBs were exposed for 24 hours to measure $\mathrm{LDH}$, showing significant neurotoxicity at only $200 \mu \mathrm{M}$ (Fig. 1). 
Table 1. Experimental conditions of reverse transcription-polymerase chain reaction (RT-PCR) analysis

\begin{tabular}{|c|c|c|c|}
\hline Gene & Primer sequence $5^{\prime} \rightarrow 3^{\prime}$ & Temperature $\left({ }^{\circ} \mathrm{C}\right)$ & Number of cycle \\
\hline IL- $1^{\mathrm{a}}$ & Forward: ATGGCGAGAAGTACCTAAGCT & 58 & 28 \\
\hline IL- $6^{\mathrm{b}}$ & $\begin{array}{l}\text { Reverse: ACACAAATTGCATGGTGAAGT } \\
\text { Forward: ATGAACTCCTTCTCCACAAGCGC } \\
\text { Reverse: GAAGAGCCCTCAGGCTGGACTG }\end{array}$ & 62 & 25 \\
\hline TNF- $a^{c}$ & $\begin{array}{l}\text { Forward: ATGAGCACAGAAAGCATGATC } \\
\text { Reverse: TACAGGCTTGTCACTCGAATT }\end{array}$ & 60 & 30 \\
\hline GAPDH $^{\mathrm{d}}$ & $\begin{array}{l}\text { Forward: GCACAGTCAAGGCCGAGAAT } \\
\text { Reverse : GCCTTCTCCATGGTGGTGAA }\end{array}$ & 58 & 25 \\
\hline
\end{tabular}

${ }^{\mathrm{a}}$ Interleukin- $1 ;{ }^{\mathrm{b}}$ Interleukin-6; ${ }^{\circ}$ Tumor necrosis factor- $\alpha ;{ }^{\mathrm{d}}$ Glyceraldehyde-3-phosphate dehydrogenase.

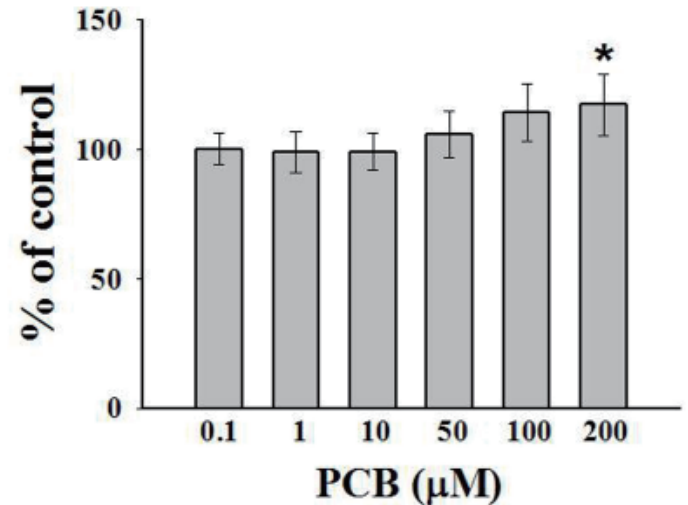

Fig. 1. Lactate dehydrogenase (LDH) depending on the different doses of PCBs exposure. $0.1 \mu \mathrm{M}$ to $200 \mu \mathrm{M}$ PCBs were exposed for 24 hours to measure $\mathrm{LDH}$, showing significant neurotoxicity at only $200 \mu \mathrm{M}$ ${ }^{*}$ Significantly different from control at $\mathrm{p}<0.05$.

On the basis of this result, therefore, the contents showing no neurotoxicity-0.1, 1, 25, and $50 \mu \mathrm{M}$-were set for experimental exposure.

\section{Effects of protein kinase C}

When general activity of PKC was analyzed using $\left[{ }^{3} \mathrm{H}\right] \mathrm{PDBu}$, non-coplanar PCBs were found to be more active than coplanar PCBs (Table 2). While PCB 126 and PCB 169 in the coplanar structure showed no remarkable change even at $50 \mu \mathrm{M}, \mathrm{PCB}$ 4 in the non-coplanar structure had binding increased by approximately 1.5 times. The commercial mixture containing a large amount of non-coplanar PCBs, Aroclor 1256, also showed the same level of increase in binding to PCB 4. It was therefore suggested that PCB causing PKC activity within neuronal cells had a significant non-coplanar structure. When PKC congeners playing an important role for the signaling system were analyzed with western blot, PKC- $\alpha$ made no apparent migration in PCB 126 or PCB 169 but made apparent migration from cytosol to membrane in PCB 4 and Aroclor 1256 (Fig. 2A). Similar observations were made from PKC- $\beta$ II (Fig. 2B).
Table 2. $\left[{ }^{3} \mathrm{H}\right]$ phorbol-12,13-dibutyrate (PDBu) binding following the exposure of substances (percentage of control)

\begin{tabular}{lcrlr}
\multicolumn{1}{c}{ Substances } & $\mathbf{0 . 1} \boldsymbol{\mu M}$ & $\mathbf{1} \boldsymbol{\mu M}$ & $\mathbf{2 5} \boldsymbol{\mu M}$ & $\mathbf{5 0} \boldsymbol{\mu M}$ \\
\hline PCB $^{\mathrm{a}} 126$ & $102 \pm 6$ & $98 \pm 8$ & $108 \pm 11$ & $112 \pm 15$ \\
PCB $^{\mathrm{a}} 169$ & $105 \pm 9$ & $104 \pm 7$ & $116 \pm 12$ & $114 \pm 11$ \\
PCB $^{\mathrm{a}} 4$ & $104 \pm 6$ & $108 \pm 7$ & $118 \pm 8$ & $148 \pm 8$ \\
Aroclor 1256 & $98 \pm 4$ & $111 \pm 9$ & $121 \pm 12$ & $145 \pm 7$ \\
\hline
\end{tabular}

While PCB 126 and PCB 169 in the coplanar structure showed no remarkable change even at $50 \mu \mathrm{M}, \mathrm{PCB} 4$ and Aroclor 1256 in the noncoplanar structure had binding increased by approximately 1.5 times. ${ }^{a}$ Polychlorinated biphenyl.

\section{Generation of reactive oxygen species (ROS)}

In terms of involvement of PCBs in ROS generation for neuronal cells, PCBs in the coplanar structure, such as PCB 126 and PCB 169 , increased ROS generation by 1.3 times while PCB 4 and Aroclor 1256 increased it by 1.7 times. While both PCB structures were involved in ROS generation, non-coplanar PCBs generated more ROS (Fig. 3A). When making a comparison between treatment with mercury chloride alone and co-treatment with PCBs, the former increased it by 1.2 times while co-treatment with both coplanar and non-coplanar PCBs synergistically increased ROS generation (Fig. 3B). But only marginal statistical significances were observed in the ROS generation tests.

\section{Structure-activity relationship for neuronal cell growth factors}

When extracellular matrices related to neuroendocrine hormone control disorders were analyzed using RT-PCR, mRNA of RC-3 showed no change in PCB 126 or PCB 169 but increased in noncoplanar PCBs, such as PCB 4 and Aroclor 1256, suggesting that a structure-activity relationship existed (Fig. 4A). The mRNA of GAP-43 increased in non-coplanar PCBs, such as PCB 4 and Aroclor 1256 but showed no increase in coplanar PCBs (Fig. 4B). But only marginal statistical significances were observed in the tests using growth factors. 
A
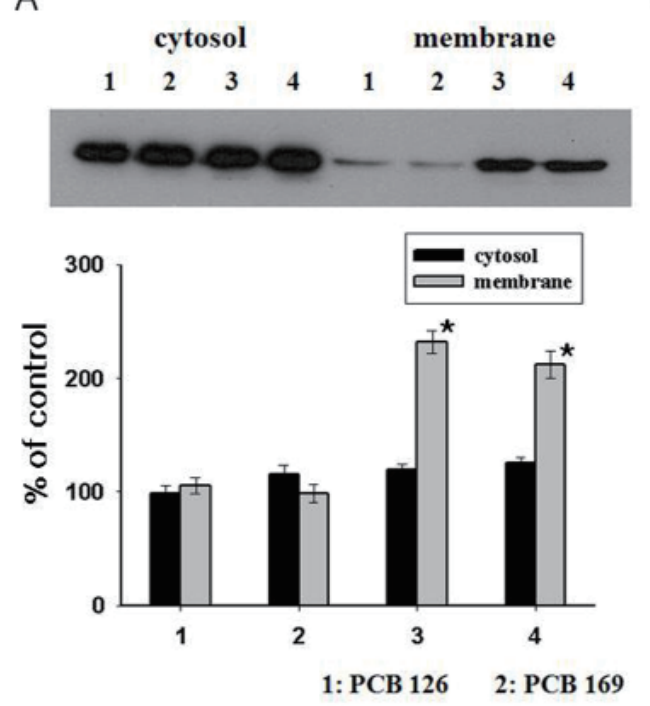

B

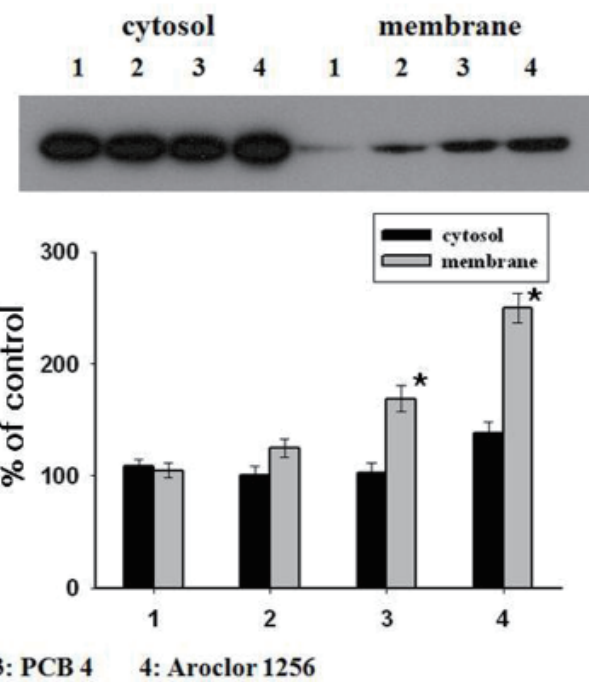

Fig. 2. Translocation of cerebellar $\mathrm{PKC}$ isoforms from the cytosol to the membrane following PCBs exposure $(50 \mu \mathrm{M})$ with western blot. (A) PKC-a made no apparent migration in PCB 126 or PCB 169 but made apparent migration from cytosol to membrane in PCB 4 and Aroclor 1256. (B) Since similar observation was made from PKC$\beta I I$, non-coplanar PCBs exerted greater effects on neuronal cells. *Significantly different from control at $\mathrm{p}<0.05$.
A

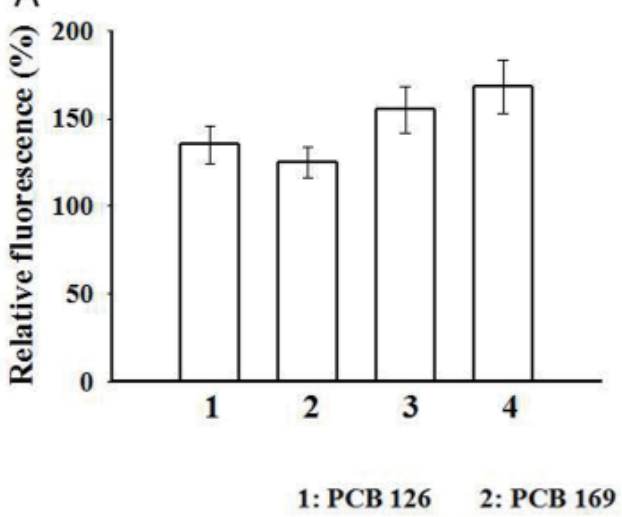

$\mathrm{B}$

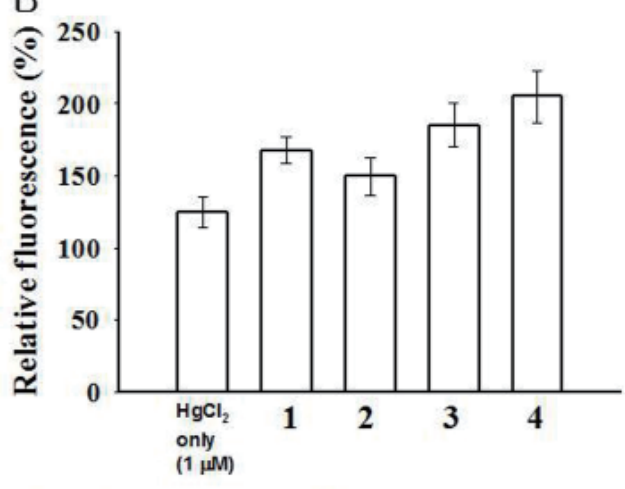

Fig. 3. Relative fluorescence to dimethyl sulfoxide (DMSO) control as a measure for formation of ROS following PCBs exposure (50 $\mu \mathrm{M})$ without (A) and with (B) $\mathrm{HgCl}_{2}$. (A) Coplanar PCBs (PCB 126 and PCB 169) increased it by 1.3 times while non-coplanar PCBs (PCB 4 and Aroclor 1256) increased it by 1.7 times. (B) When making a comparison between treatment with mercury chloride alone and co-treatment with PCBs, the former increased it by 1.2 times while co-treatment with both coplanar and non-coplanar PCBs synergistically increased ROS generation.

\section{DISCUSSION}

PCBs disrupt control of neuroendocrine systems, such as thyroid hormone (T4), serotonin, and dopamine in the brain, and also exert effects on the secondary messenger related to the signaling pathway in the nervous system. A typical example of disruption in the neuroendocrine systems by PCBs is a decrease in thyroid hormone, which is known to control PKC activity through RC-3 which is the PKC matrix present in the brain alone [15], and the decrease in thyroid hormone is known to be closely related to activity of PKC [18]. PKC also plays an important role in main action mechanisms of the neurotoxic symptoms of PCBs such as motor dysfunction and decreased learning ability and memory. The cerebellum was used as the target area for experiment since the neurotoxicities of PCBs are closely related to the cerebellum. Since the brain of newborn babies at the active growth phase is especially sensitive to the effect of neurotoxicity, this study used a 7-day-old cerebellar granule cell at the active growth phase as an experimental model.

In terms of $\left[{ }^{3} \mathrm{H}\right] \mathrm{PDBu}$ binding, which means $\mathrm{PKC}$ migration to membrane for binding, non-coplanar PCBs were more influential on PKC activation than coplanar PCBs. It was therefore suggested that there was structure-activity relationship in the PKC-related signaling pathway. Dependence of an Ah receptor is important in 
A

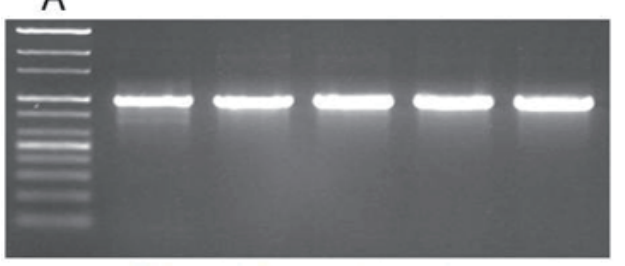

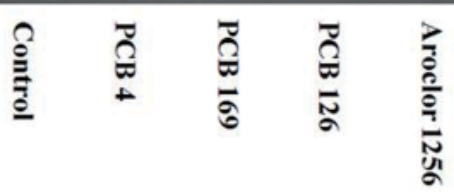

B

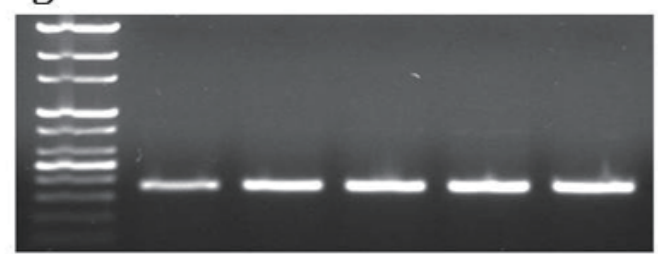

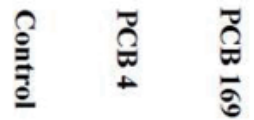

Fig. 4. RT-PCR analysis of RC-3 (A) and GAP-43 (B) with PCBs (50 $\mu \mathrm{M})$. (A) mRNA of RC-3 made no change in PCB 126 or PCB 169 but increased in non-coplanar PCBs (PCB 4 and Aroclor 1256). (B) GAP-43 with wide distribution principally in axon increased mRNA in non-coplanar, while mRNA didn't increase in coplanar PCBs. Control represents dimethyl sulfoxide (DMSO) treatment only. establishing basis for comparison risk assessment of neurotoxicity of environmental pollutants with the existing Equivalency Factor (TEF) value. Therefore, the different effects based on the structure alone in this study may be very useful in predicting possibility of neurotoxicity.

As for PCBs-induced PKC activity using western blot, PKC- $\alpha$ and $\beta I I$ were higher than other PKC congeners, therefore they may be usable as indicators of the neurotoxic effects according to the PCBs structure. They can also give an opportunity to discover target substances of PCBs, possibly contributing to the understanding of mechanism of the signaling pathway in the PCBs-related neurotoxicity.

In the ROS assay, non-coplanar PCBs increased ROS generation more than coplanar PCBs. This implies that damage to neuronal cells by PCBs was related to structure-activity. There were greater increases in ROS generations with mercury chloride regardless of the PCBs structure. So there is more damage to the nervous system caused by PCBs exposure when the existing neurotoxic substances are present. This implies that as for daily exposure to PCBs via industrial products, intake of foods possibly high in mercury, such as tuna and shark, can increase damage to the nervous system.

RC-3 and GAP-43 play an important role in controlling intracellular calcium concentration and are also closely related to PKC activity. When PCBs-induced changes of RC-3 and GAP-43 were analyzed using RT-PCR, non-coplanar PCBs increased RC-3 and GAP-43 while coplanar PCBs made no significant change. These results are assumed not to be mediated by an Ah receptor but to be involved in a specific action mechanism of non-coplanar PCBs. The fact that the increase in GAP-43 is irrelevant to an Ah receptor implies that GAP-43 is playing a specific role in noncoplanar PCBs-induced PKC activity and intracellular calcium concentration. Therefore, any change in growth-related factors, such as RC-3 and GAP-43, in the growth-phase brain cells may be used as an indicator determining coplanar and non-coplanar structure-activity relationship in PCB mixture.
This study obtained the cerebellar granule cells from a 7-dayold SD rat and secured a technique for isolating, purifying, and culturing over $90 \%$ pure neurons to study an intracellular mechanism for many compounds related to neurotoxicity. This study also obtained a growth-phase brain cell model to screen neurotoxic substances to which the cells were vulnerable in the growth period. PCBs-induced neurotoxic mechanism for the fetus or infant group has been rarely known. This study indicate that non-coplanar PCBs were an important neurotoxic substance in the brain cells by exerting greater effects on PKC activity and neuronal cell growth factors in the growth-phase cerebellar cells than coplanar PCBs.

The results from this study can provide the base for screening coplanar and non-coplanar structures among PCB mixtures present in environment or foods. They are also assumed to be usable in understanding and distinguishing neurotoxic mechanisms of other similar environmental pollutants this study didn't deal with. The results will help securing structure-activity relationship (SAR) of PCBs, efficiently screening neuroendocrine disrupting factors present in foods or environment, and contributing to improvement in efficiency of risk assessment.

\section{REFERENCES}

1. Safe SH (1994) Polychlorinated biphenyls (PCBs): environmental impact, biochemical and toxic responses and implications for risk assessment. Crit Rev Toxicol 24:87-149

2. Yang JH, Rhim JS (1995) 2,3,7,8-Tetrachlorodibenzo-pdioxin: molecular mechanism of carcinogenesis and its implication in human in vitro model. Crit Rev Oncol Hematol 18:111-127

3. Yang JH (1999) Expression of dioxin-responsive genes in human endometrial cells in culture. Biochem Biophys Res Commun 257:259-263

4. Yang JH, Kodavanti PR (2001) Possible molecular targets 
of halogenated aromatic hydrocarbons in neuronal cells. Biochem Biophys Res Commun 280:1372-1377

5. Kodavanti PR, Tilson HA (1997) Structure-activity relationships of potentially neurotoxic PCB congeners in the rat. Neurotoxicology 18:425-441

6. Tithof PK, Schiamberg E, Peters-Golden M, Ganey PE (1996) Phospholipase A2 is involved in the mechanism of activation of neutrophils by polychlorinated biphenyls. Environ Health Perspect 104:52-58

7. Kodavanti PR, Ward TR, McKinney JD, Tilson HA (1996) Inhibition of microsomal and mitochondrial $\mathrm{Ca}^{2+}$-sequestration in rat cerebellum by polychlorinated biphenyl mixtures and congeners. Structure-activity relationships. Arch Toxicol 70:150-157

8. Tilson HA, Kodavanti PR (1997) Neurochemical effects of polychlorinated biphenyls: an overview and identification of research needs. Neurotoxicology 18:727-743

9. Rahaman SO, Ghosh S, Mohanakumar KP, Das S, Sarkar PK (2001) Hypothyroidism in the developing rat brain is associated with marked oxidative stress and aberrant intraneuronal accumulation of neurofilaments. Neurosci Res 40:273-279

10. Nebert DW, Roe AL, Dieter MZ, Solis WA, Yang Y, Dalton TP (2000) Role of the aromatic hydrocarbon receptor and [Ah] gene battery in the oxidative stress response, cell cycle control, and apoptosis. Biochem Pharmacol 59:65-85

11. Weisglas-Kuperus N (1998) Neurodevelopmental, immunological and endocrinological indices of perinatal human exposure to PCBs and dioxins. Chemosphere 37:1845-1853
12. Frost E, Kiernan BW, Faissner A, ffrench-Constant C (1996) Regulation of oligodendrocyte precursor migration by extracellular matrix: evidence for substrate-specific inhibition of migration by tenascin-C. Dev Neurosci 18:266-273

13. Ide CF, Scripter JL, Coltman BW, Dotson RS, Snyder DC, Jelaso A (1996) Cellular and molecular correlates to plasticity during recovery from injury in the developing mammalian brain. Prog Brain Res 108:365-377

14. Lai C, Brow MA, Nave KA, Noronha AB, Quarles RH, Bloom FE, Milner RJ, Sutcliffe JG (1987) Two forms of 1B236/ myelin-associated glycoprotein, a cell adhesion molecule for postnatal neural development, are produced by alternative splicing. Proc Natl Acad Sci U S A 84:4337-4341

15. Iñiguez MA, Rodriguez-Peña A, Ibarrola N, Aguilera M, Muñoz A, Bernal J (1993) Thyroid hormone regulation of RC3, a brain-specific gene encoding a protein kinase-C substrate. Endocrinology 133:467-473

16. Yang JH, Vogel C, Abel J (1999) A malignant transformation of human cells by 2,3,7,8-tetrachlorodibenzo-p-dioxin exhibits altered expressions of growth regulatory factors. Carcinogenesis 20:13-18

17. Voie OA, Fonnum F (2000) Effects of polychlorinated biphenyls on production of reactive oxygen species (ROS) in rat synaptosomes. Arch Toxicol 73:588-593

18. Yang JH, Derr-Yellin EC, Kodavanti PR (2003) Alterations in brain protein kinase $\mathrm{C}$ isoforms following developmental exposure to a polychlorinated biphenyl mixture. Brain Res Mol Brain Res 111:123-135 